\title{
Investigation of the Effects of Anisotropic Flow of Pore Water and Multilayered Soils on Three-Dimensional Consolidation Characteristics
}

\author{
Arpan Laskar and Sujit Kumar Pal \\ Department of Civil Engineering, NIT Agartala, Jirania, India \\ Correspondence should be addressed to Arpan Laskar; arpan2k8@yahoo.co.in
}

Received 25 November 2016; Revised 10 February 2017; Accepted 22 February 2017; Published 9 March 2017

Academic Editor: Giorgio Pia

Copyright (c) 2017 Arpan Laskar and Sujit Kumar Pal. This is an open access article distributed under the Creative Commons Attribution License, which permits unrestricted use, distribution, and reproduction in any medium, provided the original work is properly cited.

\begin{abstract}
Many practical engineering problems are seriously different from the assumptions which are considered for one-dimensional consolidation test and need to concentrate on three-dimensional consolidation of soil under different boundary conditions. In this study three-dimensional consolidation tests are performed with four different anisotropic flow conditions of pore water and fifteen different combinations of horizontal layered soils. Twelve different three-dimensional consolidation tests are also performed with different soils, surrounded by anisotropic vertical soil layers on two opposite sides. From these studies, it is observed that the anisotropic flow of pore water does not have any effect on initial and final surface settlement of soil but has a significant effect during the consolidation process. The anisotropic flow of pore water during the consolidation process has an immense effect on the coefficient of consolidation. Horizontal layered soil has a great effect on both surface settlement and the rate of settlement. Vertical soil layers on two opposite sides of consolidative soil have an immense effect on the horizontal movements of consolidating soil, finally affecting the resultant vertical settlement of soil. Vertical anisotropic surrounding soil layers also have an effect on the rate of consolidation settlement.
\end{abstract}

\section{Introduction}

In situ soils are subjected to different drainage conditions. The anisotropic permeability and drainage conditions influence the consolidation characteristics of these in situ soils. Coefficient of consolidation evaluated by different methods by considering different drainage conditions in the same soil could be quite different [1]. At the time of evaluation of rate of consolidation, proper drainage condition has not been reflected because prediction of coefficient of consolidation is still calculated based on traditional oedometer test, where only vertical drainage is considered. Simulating field drainage conditions at the laboratory consolidation test may help to predict more accurate rate of consolidation. In case of traditional oedometer test, measurements are restrained to vertical direction only and thus the calculated rate of extraction of pore water will be less as compared to in situ rate of extraction of pore water. In in situ soils there may have been different drainage conditions as shown in Figure 1. Consolidation characteristics of soil are depending on the drainage conditions as well as vertical and horizontal movements of soil particles during the consolidation. By considering traditional oedometer test, vertical drainage through the soil and vertical movement of soil particles are considered, and radial flow of water and radial movement of soil particles are ignored; the traditional oedometer test results do not highlight appropriate values of consolidation characteristics.

Nonhomogeneity of in situ soil is always overlooked at the time of laboratory or analytical evaluation of consolidation characteristics. As nonhomogeneous characteristics of soil are not considered, these methods are always providing an unsatisfactory result of consolidation characteristics.

In this paper, it is proposed to use an apparatus which will simulate field conditions suitably at the time of laboratory consolidation test and predict rate of consolidation more precisely. Three-dimensional (3D) consolidation test, 


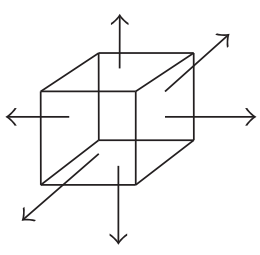

Case i

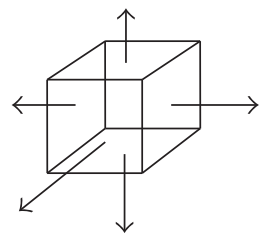

Case ii

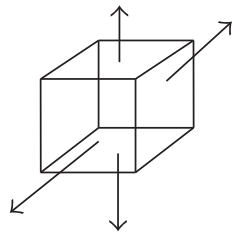

Case iii

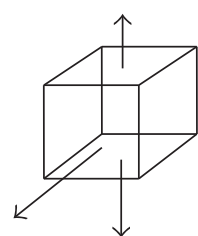

Case iv

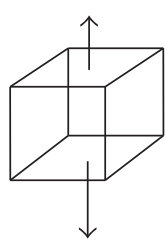

Case v
Figure 1: Anisotropic flow directions of pore water through soil under 3D consolidation.

where it is possible to control the direction of drainage and maintain nonhomogeneity of soil, can predict more accurate consolidation characteristics.

Over the years different researchers have presented their studies on development of concepts for evaluating consolidation characteristics simulating field conditions. By considering coupling between solid and fluid, Biot (1941) first introduced the general theory of three-dimensional consolidation [2]. Based on Biot's three-dimensional consolidation theory different investigators had developed different analytical solutions. Edelman (1953) studied an analytical solution of consolidation taking the nonlinear properties of soil into account by assuming Young's modulus of soil, which varies linearly with depth but permeability of the soil was assumed constant with depth [3]. Skempton and Bjerrum (1957) proposed a correction factor $(\mu)$ to bring three-dimensional consolidation effects in one-dimensional consolidation settlement [4]. Hwang and Witczak (1984) developed a numerical procedure for probabilistic solution of consolidation of soils with multidimensional soil variability and water flow [5]. Ai and Cheng (2013) performed a numerical 3D consolidation analysis with an anisotropic permeability of a layered soil system and discussed the effects of anisotropy of permeability on the consolidation behaviour of soil [6]. Ai et al. (2013) presented an analytical solution for three-dimensional consolidation of a multilayered porous medium with anisotropic permeability by using the transfer matrix method and they showed that the layered characteristics and the anisotropy of permeability had great effect on the surface settlement [7].

All the previous investigations of three-dimensional consolidation were analytical or numerical based and boundary assumptions were not replicated in the field conditions. Hence, it is important to develop an experimental solution for three-dimensional consolidation problems having an anisotropic flow of water, nonhomogeneity of the soil, and lateral movement of soil particles which can replicate the in situ settlement of shallow footing.

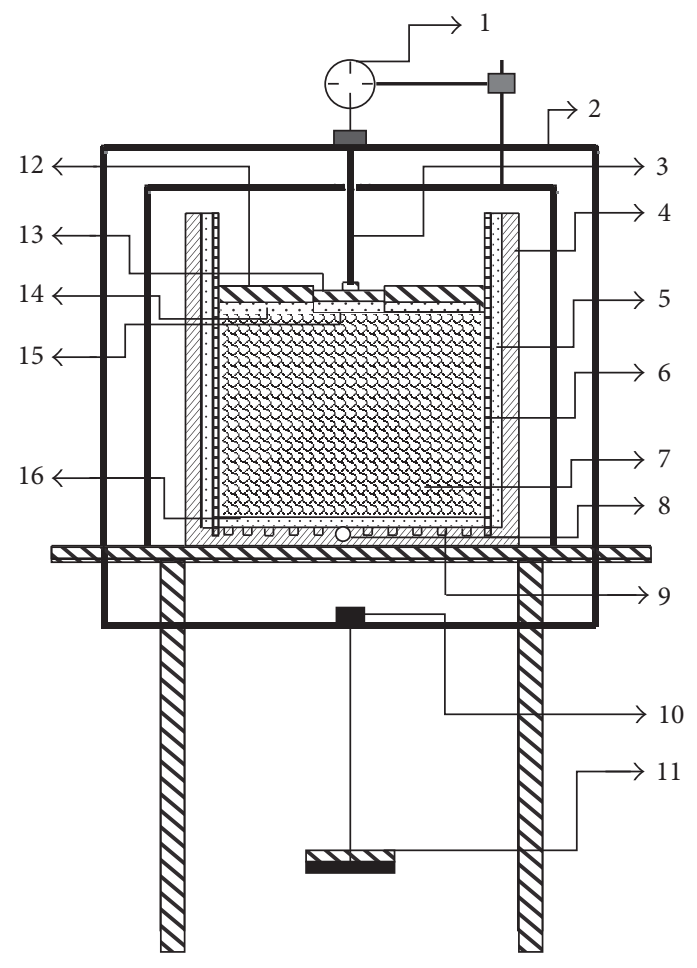

(1) Dial gauge

(2) Loading frame

(3) Plunger

(4) Consolidation tank

(5) Side porous stone plate

(6) Perforated cast iron box

(7) Soil sample

(8) Outlet

(9) Bottom thread connected to outlet

(10) Lever loading system

(11) Load

(12) Initial sitting loading plate with $61 \mathrm{~mm}$ diameter centre hole

(13) Perforated loading plate

(14) Top porous stone bellow the initial sitting loading plate with $61 \mathrm{~mm}$ diameter centre hole

(15) Top porous stone bellow the perforated loading plate

(16) Bottom porous stone

FIGURE 2: Schematic diagram of developed 3D consolidation apparatus.

\section{Aim and Scope of the Study}

The aim of the study is to find out the consolidation characteristics under different boundary conditions which can simulate actual field conditions. In this paper a new laboratory three-dimensional consolidation apparatus is shown in Figure 2, by which it is possible to control the boundary conditions at the time of consolidation process. By this apparatus it is feasible to control direction of horizontal flow of water through soil, anisotropy of soil, and lateral movement of soil particles. To achieve the desired aim, different consolidation cells made with perforated and solid cast iron sheets (Figure 3) have been used. The inner crosssectional size of perforated box is $300 \mathrm{~mm} \times 300 \mathrm{~mm}$, kept 


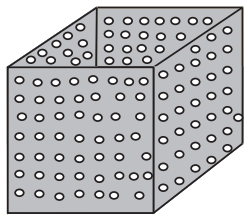

(i)

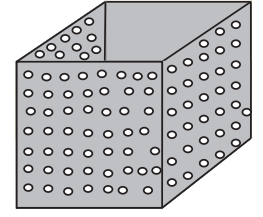

(ii)

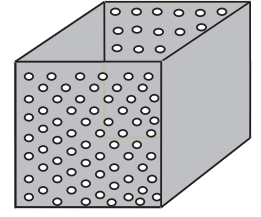

(iii)

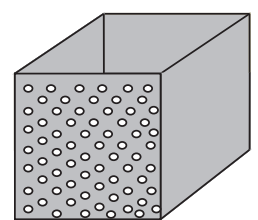

(iv)

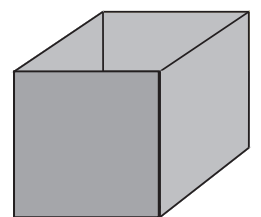

(v)
FIGURE 3: Cast iron consolidation cells made with perforated and solid cast iron sheets.

five times the cross-sectional size of the loading plate to keep soil out of boundary effects, providing perforation through different direction in perforated boxes; it is possible to control anisotropic flow of water through the soil at the time of the laboratory consolidation test.

\section{New Consolidation Apparatus}

Figure 2 shows the newly developed three-dimensional consolidation apparatus. Following are the different parts of this developed consolidation apparatus.

3.1. Consolidation Cell. The consolidation cell is made of noncorrosive cast iron. The inner and outer dimensions of the consolidation cell are $300 \mathrm{~mm} \times 300 \mathrm{~mm} \times 450 \mathrm{~mm}$ (height) and $310 \mathrm{~mm} \times 310 \mathrm{~mm} \times 450 \mathrm{~mm}$ (height), respectively. As shown in Figure 3, five numbers of different consolidation cells are fabricated with porous and solid cast iron plates, which are open at top and bottom sides. These consolidation cells are used to test the soil samples under controlled drainage conditions.

3.2. Porous Stone. Porous stones are placed at the top, bottom, and four consecutive sides of the soil specimen and these stones are made of silicon carbide. The size of bottom porous stone is $299 \mathrm{~mm} \times 299 \mathrm{~mm} \times 12 \mathrm{~mm}$ (thickness). The size of top porous stone is the same as bottom porous stone but there is a hole of $61 \mathrm{~mm}$ diameter at the centre through which another $60 \mathrm{~mm}$ diameter porous stone can be inserted. A sheet of Whatman filter paper of size equal to that of the stones is placed between the stone and the soil surface, in order to prevent movement of soil particles.

3.3. Loading Plate. A $60 \mathrm{~mm}$ diameter cast iron loading plate is used to apply the load on the soil specimen. This loading plate is connected to loading frame by a plunger.

3.4. Plate to Apply Initial Seating Load. A cast iron plate is fabricated of cross-sectional area of $299 \mathrm{~mm} \times 299 \mathrm{~mm}$ with a $61 \mathrm{~mm}$ diameter centre hole like top porous stone. This plate is fabricated in such a way that a $0.05 \mathrm{~kg} / \mathrm{cm}^{2}$ seating load can be applied by this plate on top of the specimen except $61 \mathrm{~mm}$ diameter centre hole.

3.5. Consolidation Tank. A concrete consolidation tank is fabricated within which consolidation cell is placed containing the specimen between the top and bottom porous stones. The tank is capable of being filled with water to a level higher than the top of the upper porous stone, having an axial vertical load applied to the top of the specimen and allowing measurement of the settlement of the specimen on its central axis.

3.6. Dial Gauge. A dial gauge is used which can read the values to an accuracy of $0.01 \mathrm{~mm}$.

3.7. Loading Device. A lever loading system as shown in Figure 2 is fabricated which enables us to apply vertical force axially in suitable increment to the test specimen through a plunger. This device is capable of maintaining specified loads for long periods of time while the specimen is deforming.

\section{Theoretical Considerations}

Assumptions made on newly developed three-dimensional consolidation test are as follows:

(1) The soil layers are homogeneous and the soil properties are isotropic.

(2) The soil layers are two-faced saturated.

(3) Vertical and horizontal movements of soil particles are allowed during the process of consolidation.

(4) The compression of the soil layer is due to the change in volume only, which in turn is due to the squeezing out of water from void space in vertical as well as in horizontal directions.

(5) Darcy's law is valid.

(6) In case of plastic settlement, if all the soil particles are interconnected then vertical movement of soil particles occurs due to horizontal movements of underneath soil particles and without horizontal movement of underneath soil particles, no vertical movement of top soil particles occurs.

(7) Lower boundary of stress remains constant throughout the consolidation process.

\section{Testing Materials and Program}

Three different types of soils are used in this investigation. A series of standard classification tests is carried out to categorize these test materials. Basic properties of the sandy soil are presented in Table 1 and the physical properties along with maximum dry density (MDD) and optimum moisture content (OMC) using standard Proctor compaction energy of other two types of soils are listed in Table 2.

Five different 3D consolidation tests are performed by using silty-clay soil under different flow conditions as shown in Figure 1. Fifteen different 3D consolidation tests are performed on horizontal layered soils which are clearly shown in 
TABLE 1: Basic properties of the sandy soil.

\begin{tabular}{lcccccccc}
\hline $\begin{array}{l}\text { Type of } \\
\text { soil }\end{array}$ & Grain size & $\begin{array}{c}\text { Specific } \\
\text { gravity }\end{array}$ & $e_{\max }$ & $e_{\min }$ & $\begin{array}{c}\text { Fines content } \\
(\%)\end{array}$ & $\begin{array}{c}\text { Shell content } \\
(\%)\end{array}$ & $\begin{array}{c}D_{50} \\
e=0.40(\mathrm{~m} / \mathrm{sec})\end{array}$ \\
\hline River sand & Sand, $100 \%$ & 2.66 & 0.84 & 0.30 & 1.30 & 0.0 & 0.85 & $2.11 E-01$ \\
\hline
\end{tabular}

TABLe 2: Physical properties and compaction characteristics (at standard Proctor) of soils.

\begin{tabular}{lcc}
\hline Properties & Silty-sand soil & Silty-clay soil \\
\hline Specific gravity & 2.58 & 2.50 \\
Liquid limit (\%) & 25.30 & 53.35 \\
Plastic limit (\%) & 19.03 & 29.32 \\
Plasticity index (\%) & 4.27 & 24.03 \\
Grain size & & \\
Sand (\%) & 61.60 & 4.86 \\
Silt (\%) & 21.68 & 41.46 \\
Clay (\%) & 16.72 & 53.68 \\
Optimum moisture content & 13.10 & 25.75 \\
(OMC) (\%) & 1.88 & \\
Maximum dry density (MDD) & & 1.56 \\
(gm/cm ${ }^{3}$ ) & $8.87 E-7$ & $3.39 E-8$ \\
Permeability at MDD (cm/sec) & &
\end{tabular}

Figure 4 and twelve different 3D consolidation tests are performed on soils comprised of anisotropic vertical soil layers on two opposite sides which are also clearly shown in Figure 5.

\section{Specimen Preparation and Experimental Procedures}

The soils used for the experiments are coarse-grained sandy soil, silty-sand soil, and silty-clay soil of Agartala, Tripura, India. The properties of all the three soils are listed in Tables 1 and 2. Three-dimensional consolidation tests are performed on silty-clay soil with different horizontal flow conditions as shown in Figure 1 and to achieve these desired flow conditions during three-dimensional consolidation, different cast iron consolidation cells as shown in Figure 3 are used in the developed 3D consolidation apparatus. These different cast iron consolidation cells provide different hydraulic anisotropy during the 3D consolidation of soil. For Case i, Case ii, Case iii, Case iv, and Case v of Figure 1, cast iron consolidation cells (i), (ii), (iii), (iv), and (v) of Figure 3 are, respectively, used during the consolidation in the developed 3D consolidation apparatus. Coarse-grained sandy soil is used at density of $1.90 \mathrm{gm} / \mathrm{cc}$ and two other soil samples are remoulded at a maximum dry density (MDD) in a cast iron consolidation cell (i) of Figure 3 in different layers which are shown in Figures 4 and 5, and these soil samples are considered as an ideal two-faced soil system during the test. The inner sides of the cast iron consolidation cell are covered by filter paper before moulding the soil sample. After moulding the sample, four consecutive sides of the cast iron consolidation cell are covered by porous stone plates as shown in Figure 2 (side porous stone plate). Over the soil sample, filter paper, porous stone, and cast iron plate of cross-sectional size of $299 \mathrm{~mm}$ $\times 299 \mathrm{~mm}$, with centre hole of $61 \mathrm{~mm}$ diameter, are placed one above the other. The cast iron plate is placed over the soil specimen to apply initial seating pressure of $0.05 \mathrm{~kg} / \mathrm{cm}^{2}$. A filter paper, a porous stone, and a perforated loading plate of $60 \mathrm{~mm}$ diameter have been placed consecutively through the $61 \mathrm{~mm}$ diameter centre hole. Load is applied by the lever loading frame system to the top perforated loading plate of $60 \mathrm{~mm}$ diameter through a plunger connecting the loading frame and perforated loading plate. Initially, $0.05 \mathrm{~kg} / \mathrm{cm}^{2}$ stress is applied as a seating load and kept for 48 hours to saturate the soil sample. After 48 hours, $0.5,1.0,2.0,4.0$, and $8.0 \mathrm{~kg} / \mathrm{cm}^{2}$ stresses are consecutively applied on the soil sample and each stress is applied for 24 hours. With the application of stresses on soil, vertical settlements corresponding to different time interval are measured by a strain gauge.

\section{Test Results and Analysis}

Experiments are conducted on two-faced soil samples. Coarse-grained sandy soil and two other different types of soils have been used in this study. Different properties of the sandy soil are presented in Table 1 and the physical properties along with maximum dry density (MDD) and optimum moisture content (OMC) using standard Proctor compaction energy of other two types of soils are listed in Table 2. Three-dimensional consolidation tests are conducted with the developed three-dimensional consolidation apparatus as shown in Figure 2, under different anisotropic boundary conditions.

7.1. Compressibility Calculations. In case of one-dimensional consolidation test, compressibility has been calculated by height of solid method. In the developed three-dimensional consolidation test, volume change method has been adopted to determine compressibility.

In developed three-dimensional consolidation apparatus $6 \mathrm{~cm}$ diameter loading plate has been used to apply the load on the soil sample. Below the $6 \mathrm{~cm}$ diameter circular loading plate, 2:1 method of stress distribution has been considered. Lower boundary of stressed area below the loading plate has been considered 1.5 times the diameter of loading plate and it also called seat of settlement [8]. Figure 6 has shown the considered stressed area below the loading plate.

As per the assumptions, the compression of the soil layer is due to the change in volume only, which in turn is due to the squeezing out of water from void space in vertical as well as in horizontal directions. The vertical settlement of perforated loading plate is the resultant effect of total volume change of that sample under certain load and so that the volume 

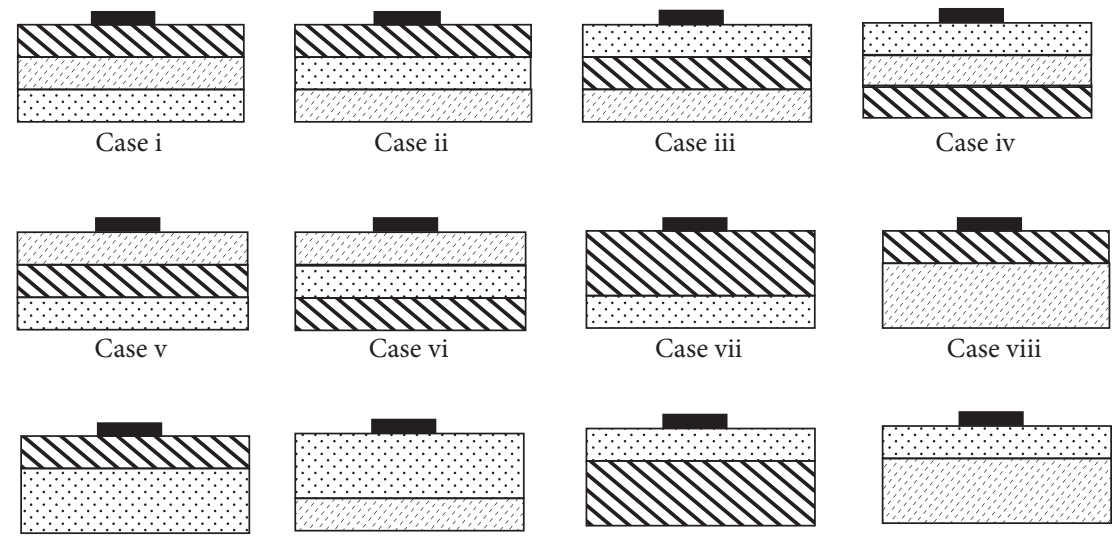

Case ix

Case $\mathrm{x}$

Case xi

Case xii

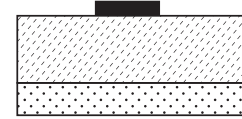

Case xiii

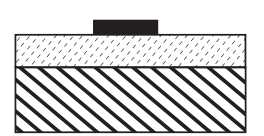

Case xiv

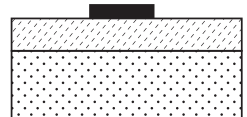

Case $\mathrm{xv}$

NW Silty-clay soil

Sandy oil

Silty-sand soil

FIGURE 4: Arrangements of horizontally layered anisotropic soils.

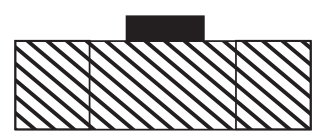

Case i

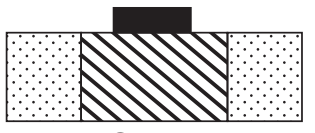

Case iv

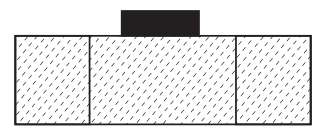

Case vii

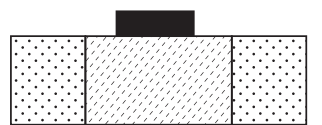

Case $\mathrm{x}$

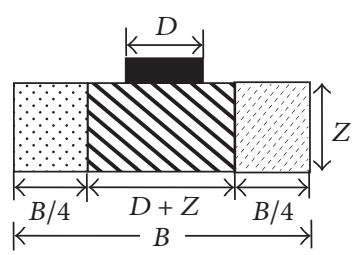

Case ii

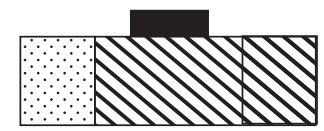

Case $v$

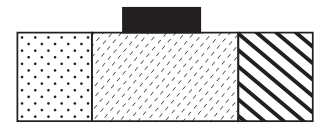

Case viii

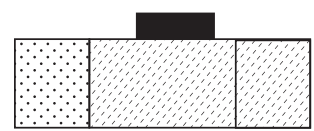

Case $\mathrm{xi}$

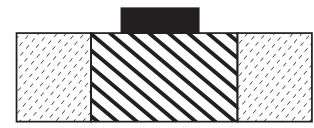

Case iii

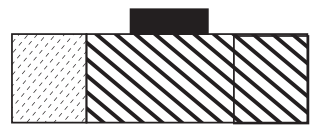

Case vi

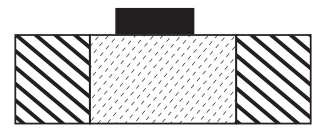

Case ix

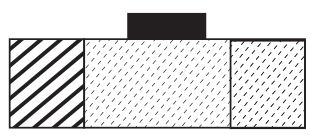

Case xii

MV Silty-clay soil

Sandy oil

Silty-sand soil

FIGURE 5: Arrangements of vertically layered anisotropic boundary soils. 


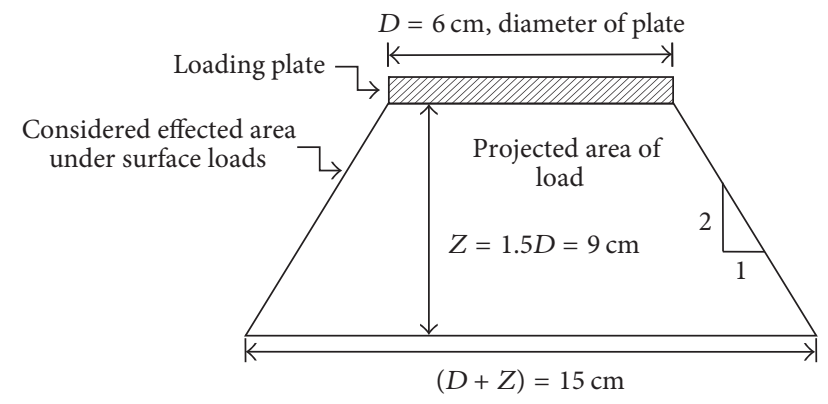

FIGURE 6: 2:1 load distribution below circular loading plate.

of settlement of the perforated loading plate is the resultant volume change of that soil sample under compression.

From Figure 6, the total volume of truncated cone under stress is

$$
\begin{aligned}
\left(V_{0}\right) & =\frac{1}{3} \pi\left(r_{1}^{2}+r_{1} r_{2}+r_{2}^{2}\right) h \\
& =\frac{1}{3} \pi\left\{3^{2}+(3 \times 7.5)+7.5^{2}\right\} \times 9 \mathrm{~cm}^{3} \\
& =827.02 \mathrm{~cm}^{3},
\end{aligned}
$$

where $r_{1}$ is radius of the top surface of truncated cone; $r_{2}$ is radius of the bottom surface of truncated cone; and $h$ is height of the truncated cone.

Now, maximum dry density of soil sample is $\gamma_{d}$, weight of soil solid $\left(W_{s}\right)=\left(V_{0} \times \gamma_{d}\right)$, specific gravity of soil sample is $G$, and dry volume of that soil $\left(V_{\text {dry }}\right)=w_{s} / G \gamma_{w}$. So, initial void ratio $\left(e_{0}\right)=\left(V_{0}-V_{\text {dry }}\right) / V_{\text {dry }}$.

By using this volume change concept, the change of void ratio and compression indices corresponding to the change of vertical stress for different soils under different boundary conditions are evaluated and explained in Sections 7.1.1, 7.1.2, and 7.1.3.

7.1.1. Compressibility of Soil with Different Anisotropic Flow Conditions under 3D Consolidation Test. The effect of anisotropic flow of pore water through the soil on threedimensional consolidation problems are studied herein. Figure 2 shows the developed 3D consolidation apparatus by which it is possible to perform $3 \mathrm{D}$ consolidation tests under anisotropic boundary conditions. In this study, one isotropic and four different anisotropic pore water flow conditions are considered and shown in Figure 1 to evaluate the effects of anisotropic flow conditions on 3D consolidation of soil. Figure 3 shows the different consolidation cells made with perforated and solid cast iron sheets by which it is feasible to control the flow directions of water through soil sample. In this part of study, silty-clay soil is used as a consolidative soil under different radial flow conditions and 3D consolidation tests are performed under these different flow conditions. Figure 7 shows the surface settlement at different radial flow conditions, where settlements are considerably different in the process of consolidation but the same at the initial and final stages, and that is why, the compression index $\left(C_{c}\right)$ values of silty-clay soil at different flow conditions are the same
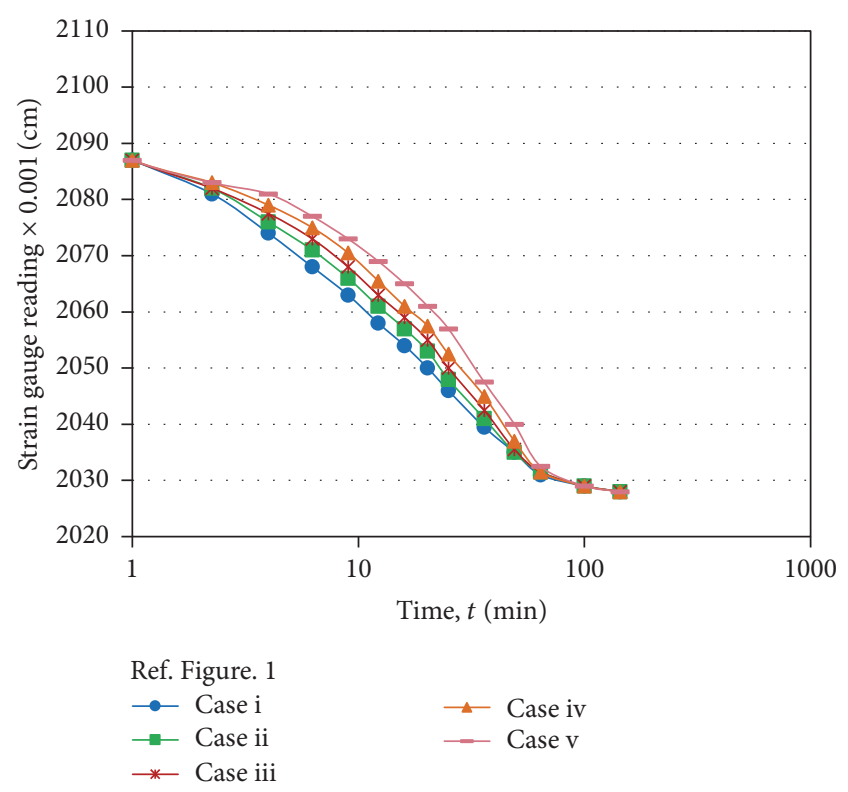

Figure 7: Comparison of surface settlements at different radial flow conditions.

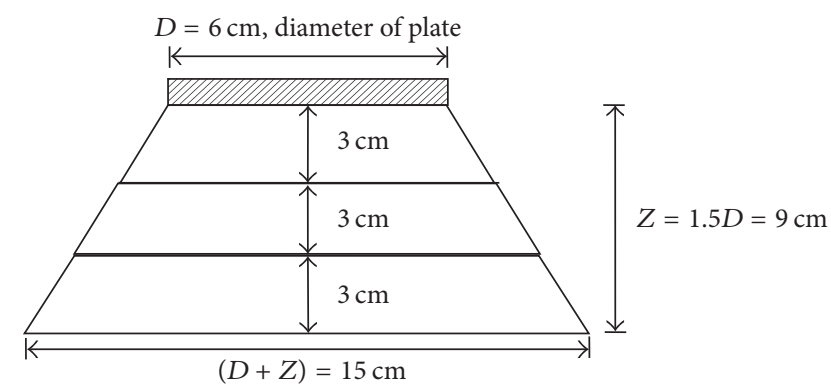

FIGURE 8: 2:1 load distribution for horizontal layered soil arrangement.

as $0.029,0.055,0.118$, and 0.302 corresponding to load interval of $0.5-1.0,1.0-2.0,2.0-4.0$, and $4.0-8.0 \mathrm{~kg} / \mathrm{cm}^{2}$, respectively.

7.1.2. Compressibility of Horizontally Layered Soils by $3 D$ Consolidation Test. Figure 4 shows the arrangements of horizontal layered soils. Three different types of soil are arranged horizontally in different layers and made fifteen different sets of layered soil. Three-dimensional consolidations are performed by using these sets of soil where free radial and vertical flow of pore water is allowed. Figure 8 shows $2: 1$ load distribution area below the loading plate for horizontal layered soil arrangements. By using volume change concept, the compression indices of these layered soils are measured. Figure 9 shows the changes of compression indices for different horizontal layered soil cases, under different vertical stress.

7.1.3. Compressibility Calculation of Soil Comprised of Anisotropic Vertical Soil Layers on Two Opposite Sides under 3D Consolidation Test. 3D consolidation tests are conducted on silty-clay soil and silty-sand soil which are comprised of anisotropic vertical soil layers on two opposite sides and the arrangements of these layers are shown in Figure 5. The 

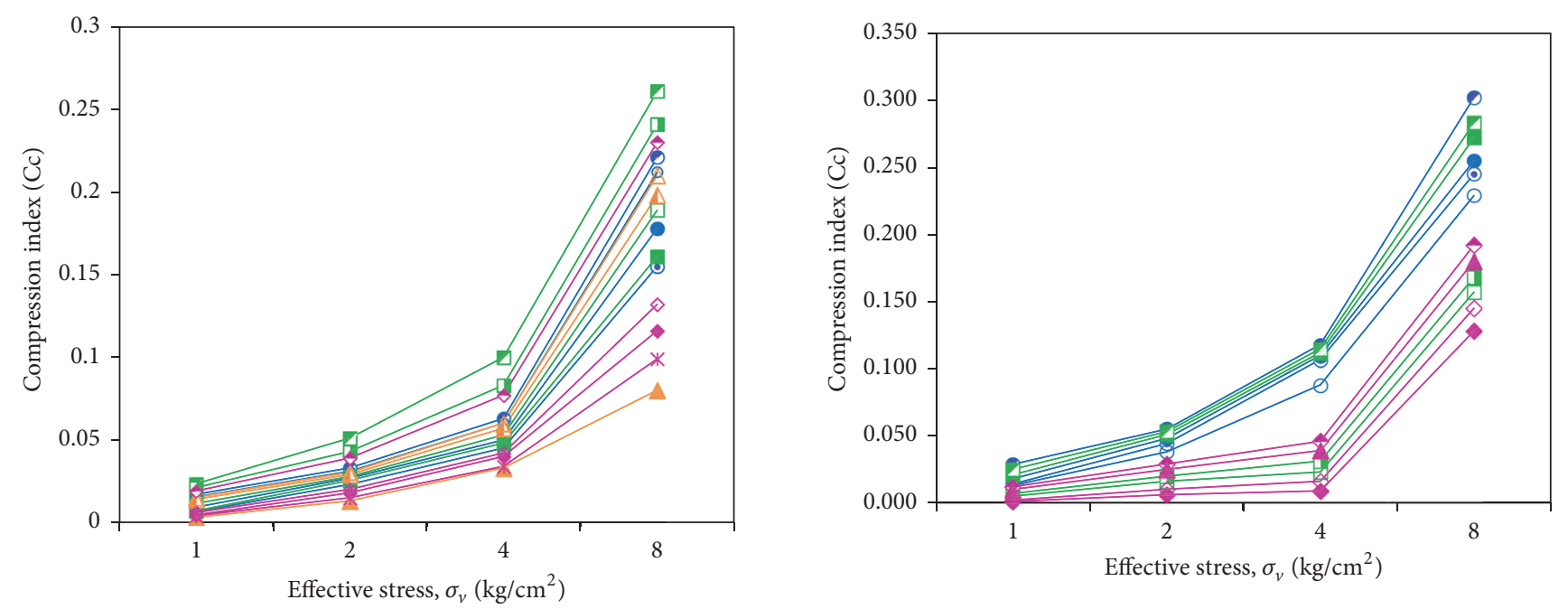

$$
\begin{aligned}
& \text { Ref. Figure. } 4 \\
& \rightarrow-\text { Case i } \rightarrow \text { Case ix } \\
& \rightarrow \text { Case ii } \rightarrow \text { Case } \mathrm{x} \\
& \rightarrow \text { Case iii } \quad \triangle \text { Case xi } \\
& -\odot-\text { Case iv } \rightarrow \text { Case xii } \\
& \square \text { Case v } \quad \diamond \text { Case xiii } \\
& \rightarrow \text { - Case vi } \rightarrow \text { Case xiv } \\
& \rightarrow-\text { Case vii } \quad * \text { Case } \mathrm{xv} \\
& -\square-\text { Case viii }
\end{aligned}
$$

$$
\begin{aligned}
& \text { Ref. Figure. } 5 \\
& \text { - - Case i } \\
& \multimap-\text { Case ii } \\
& \multimap \text { Case iii } \\
& - \text { - Case iv } \\
& \text { - Case v } \\
& \rightarrow-\text { Case vi } \\
& \square \text { Case vii } \\
& -\square-\text { Case viii } \\
& \rightarrow \text { Case ix } \\
& \multimap \text { Case } \mathrm{x} \\
& \neg \text { Case xi } \\
& ₫ \text { Case xii }
\end{aligned}
$$

FIGURE 10: Compression indices of soils having vertically layered anisotropic boundaries on two opposite sides.

FIGURE 9: Compression indices of horizontal layered anisotropic soils.

surrounding soil layers are kept out of load distribution area as shown in Case ii of Figure 5. Figure 10 shows the compression indices of silty-clay soils and silty-sand soils bounded by different soils on two opposite sides under different ranges of vertical surface load.

7.2. Calculation of Rate of Consolidation. The coefficient of consolidation $\left(c_{v}\right)$ has been determined by comparing the relationship between elapsed time $t$ and dial gauge readings of the soil sample in laboratory to the theoretical relationship between $T_{v}$ and $U$. Taylor's square root of time fitting method has been used to find out $c_{v}$ values for the three-dimensional cases. To determine the start of consolidation settlement, in the three-dimensional consolidation time-settlement curve, it is assumed that, in the early stages of consolidation, the consolidation settlement is proportional to the square root of time. Although this assumption is strictly valid for Terzaghi's one-dimensional consolidation solution, it was also found to be approximately true for the three-dimensional consolidation analysis $[9,10]$. The analytical solution for triaxial consolidation with both axial and radial drainage was proposed by Carrillo (1942) to establish the relationship between $T_{v}$ and $U$ [11]. $T_{v}$ value corresponding to $90 \%$ consolidation is obtained from the relationship of $T_{v}$ and $U$ [11].

The coefficients of consolidation have been obtained by using the time factor and $c_{v}$ relationship:

$$
c_{v}=\frac{\left(T_{v}\right)_{90} R^{2}}{t_{90}}
$$

where $R$ is radius of circle.

Now, to determine average radius of the loaded area, consider the truncated cone shape loading area as shown in Figure 6 to a cylinder having identical height and volume as the truncated cone shape loading area.

So,

$$
R=0.5 \sqrt{\left(\frac{4 V}{\pi h}\right)},
$$

where $V$ is the identical volume of truncated cone and cylinder and $h$ is the identical height of truncated cone and cylinder.

Square root of time fitting method [12] is used to determine $t_{90}$ values. At the time of three-dimensional consolidation, the coefficient of consolidation is calculated by using (2). The calculation of coefficient of consolidation of different soil under different boundary conditions is evaluated and explained in Sections 7.2.1, 7.2.2, and 7.2.3.

7.2.1. Coefficient of Consolidation of Soil under Different Flow Conditions. Coefficient of consolidation of silty-clay soil is measured under different flow conditions as shown in Figure 1. Different anisotropic flow conditions are created by using different consolidation cells as shown in Figure 3. The effects of different flow conditions on the rate of consolidation of silty-clay soil are assessed and presented in Figure 11.

7.2.2. Coefficient of Consolidation of Horizontally Layered Anisotropic Soils. Three-dimensional consolidation tests are performed by using developed consolidation apparatus on horizontal layered anisotropic soils. The sets of anisotropic soils on which three-dimensional consolidation tests are 


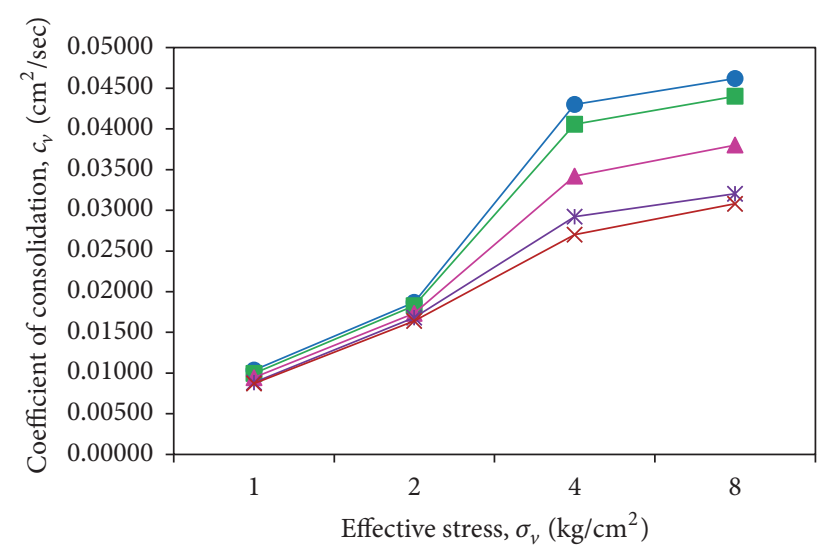

$$
\begin{array}{ll}
\text { Ref. Figure. } 1 & \\
\rightarrow-\text { Case i } & * \text { Case iv } \\
- \text { C Case ii } & \times \text { Case v }
\end{array}
$$

FIGURE 11: Coefficient of consolidation of silty-clay soil under different radial flow conditions.

conducted are shown in Figure 4. At the time of calculation of coefficient of consolidation, the load distribution area below loading plate for horizontal layered soil arrangement is shown in Figure 8. Figure 12 shows the coefficient of consolidation of different horizontal layered soil arrangements under different vertical stress.

7.2.3. Coefficient of Consolidation of Soil Comprised of Anisotropic Vertical Soil Layers on Two Opposite Sides. Threedimensional consolidation tests by using developed consolidation set-up are also conducted for silty-clay soil and siltysand soil, which are comprised of anisotropic vertical soil layers on two opposite directions as shown in Figure 5. Coefficients of consolidation of these two types of soil comprised of vertical soil layers on two opposite sides are assessed and summarised in Figure 13. Case i to Case vi of Figure 13 show the coefficient of consolidation of silty-clay soil comprised of vertical soil layers on two opposite sides and Case vii to Case xii of Figure 13 show the coefficient of consolidation of silty-sand soil comprised of vertical soil layers by two opposite sides.

\section{Discussions}

The following discussions have been made in this section:

(i) Effect of anisotropic flow of water on 3D consolidation characteristics of soil

(ii) Effect of vertical anisotropy of soil on 3D consolidation characteristics

(iii) Effect of anisotropic surrounding vertical soil layers on 3D consolidation characteristics of soil.

8.1. Effect of Anisotropic Flow of Water on 3D Consolidation Characteristics of Soil. In actual field conditions, in situ soils are not isotropic in all the directions. These anisotropic

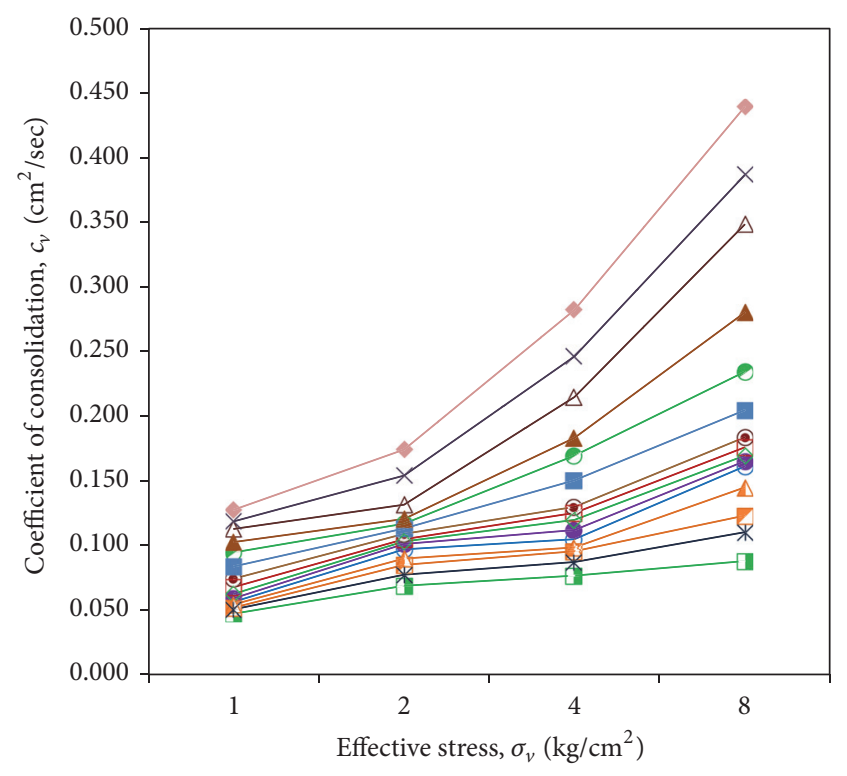

$$
\begin{aligned}
& \text { Ref. Figure. } 4 \\
& \rightarrow \text { Case i } \rightarrow \text { Case ix } \\
& \rightarrow \text { Case ii } \rightarrow \text { Case } \mathrm{x} \\
& \rightarrow-\text { Case iii } \rightarrow \text { Case xi } \\
& \rightarrow-\text { Case iv } \triangle \text { Case xii } \\
& \square \text { Case v } \quad \_ \text {Case xiii } \\
& \rightarrow \text { - Case vi } \rightarrow \text { Case xiv } \\
& \rightarrow-\text { Case vii } \quad * \text { Case } \mathrm{xv} \\
& - \text { - Case viii }
\end{aligned}
$$

FIGURE 12: Coefficient of consolidation of different horizontal layered soil system.

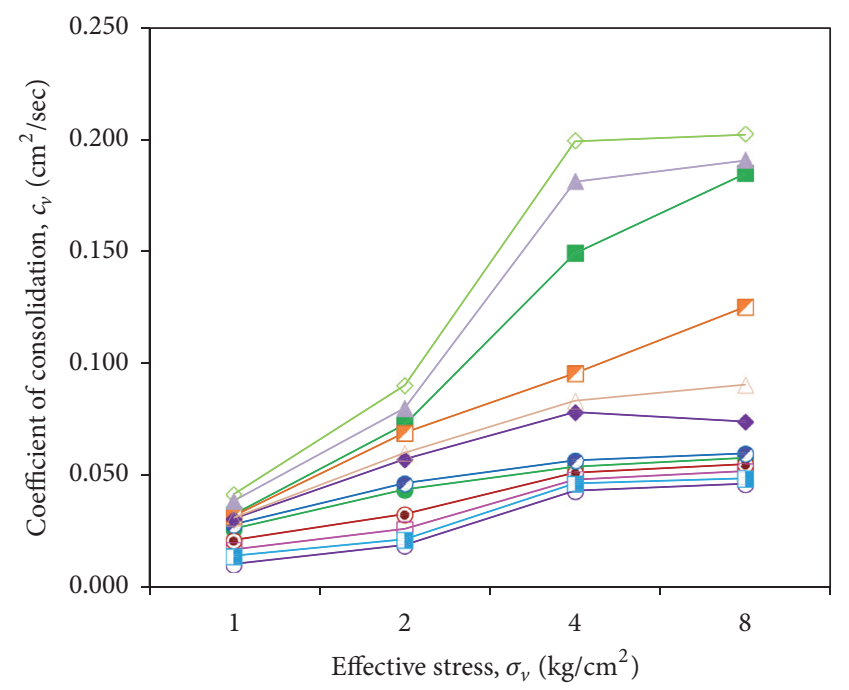

$$
\begin{array}{ll}
\text { Ref. Figure. } 5 & \\
- \text { - Case i } & - \text { Case vii } \\
\rightarrow-\text { Case ii } & \rightarrow-\text { Case viii } \\
\multimap-\text { C Case iii } & - \text { Case ix } \\
\rightarrow-\text { Case iv } & - \text { Case } \mathrm{x} \\
\square-\text { Case v } & - \text { Case } \mathrm{xi} \\
-\square-\text { Case vi } & - \text { Case xii }
\end{array}
$$

FIGURE 13: Coefficient of consolidation of soils having vertically layered anisotropic boundaries on two opposite sides. 
characteristics of soil affect the direction of pore water flow. In some of the practical cases, they may have impermeable soil layers or stones on one or several sides of the foundation soil which affect the direction of extraction of pore water at the time of the consolidation process. Consideration of the effects of anisotropy radial pore water flow on consolidation of soil is very important regarding the accurate prediction of consolidation properties. In this study, silty-clay soil compacted at maximum dry density under standard Proctor compaction is used as consolidative soil and five numbers of three-dimensional consolidation tests are conducted at different flow conditions as shown in Figure 1. These threedimensional consolidation tests under different anisotropic flow conditions are conducted by developed 3D consolidation apparatus shown in Figure 2. Five different consolidation cells are used to generate different flow conditions at the time of consolidation test (Figure 3). From Figure 3, amongst the cast iron consolidation cells, (i), (ii), (iii), (iv), and (v) are consecutively used for Case i, Case ii, Case iii, Case iv, and Case v of Figure 1. Figure 7 shows the surface settlements of siltyclay soil corresponding to different time intervals at different radial flow conditions and from the figure, it is observed that the settlements are considerably different in the process of consolidation of soil but it is same at the initial and final stages of settlement. As final settlements of the soil in all the three-dimensional consolidation tests under different radial flow conditions are the same, the compression index values are identical for all the pore water flow boundary conditions. The anisotropic flow of water does not have any effect on initial and final surface settlements but has a great influence on surface settlement during the process of consolidation and similar observation also noticed by Ai and Cheng (2013) [6].

The anisotropic flow of water has a great effect on the rate of consolidation of soil. Figure 11 shows the coefficient of consolidation of silty-clay soil under different radial flow conditions. From Figure 11, it is observed that the coefficient of consolidation value is maximum at free flow in radial and vertical directions (Case i of Figure 1), but it decreases with the increase of restriction in flow at radial directions in the present study. The rate of consolidation of any soil is purely based on the rate of extraction of water from that soil sample. As Case $\mathrm{i}$ of Figure 1 allows flow of pore water in all the directions, it has a high rate of extraction of pore water compared to other cases shown in Figure 1 and that is why Case $i$ shows maximum coefficient of consolidation value and Case $\mathrm{v}$ shows lowest coefficient of consolidation value, although the consolidative soil is identical for all the cases of Figure 1.

8.2. Effects of Vertical Anisotropy of Soil on 3D Consolidation Characteristics. The general theory of three-dimensional consolidation was first developed by Biot (1941) [2]. Analytical solutions of consolidation based on Biot's consolidation concept had been developed by many researchers such as McNamee and Gibson (1960) [10], Schiffman and Fungaroli (1965) [13], Booker and Small (1987) [14], Vardoulakis and Harnpattanapanich (1986) [15], Pan (1999) [16], Wang and Fang (2003) [17], Ai and Han (2006) [18], and Ai et al. (2008) [19]. From all the previous investigations as mentioned above, it may be said that the permeability of soil is isotropic, but this is not the case in most of the practical engineering problems. The layered soil behaviour plays a vital role in most of the in situ soil, because natural porous medium like soil may have been created by a sedimentation process. This sedimentation makes horizontal stratification layers and this makes the permeability of soil different in horizontal and vertical directions. In this study, three-dimensional consolidation tests are performed with horizontally layered soils as shown in Figure 4 by using developed 3D consolidation apparatus. In these cases, layered soils are allowed to drain out the pore water through all the directions and as a result these different soil layers can maintain their own rate of permeability at the time of the consolidation process. Figure 8 shows the load distribution area below the loading plate and vertical heights of horizontal soil layers. Three-dimensional consolidation tests are performed with fifteen different combinations of horizontal soil layers which are shown in Figure 4. Compression indices and coefficient of consolidations corresponding to different vertical stress are shown in Figures 9 and 12, respectively, for all the cases of Figure 4. By analysing all the cases of Figure 4, it is observed that compression index of horizontal layered soil mostly depends upon the compressibility of individual layers under loading area below the loading plate, but the individual compressibility of soil layers has a larger effect on compression index when the layer is situated nearer to the upper soil surface, and the effect of any layer reduced when the layer is situated far from the top soil surface. Upper soil layers are mostly affected by vertical surface load but it is also observed that lower soil layers are also having an effect on settlement characteristics of total soil system. By analysing different cases of Figure 4, like Case i to Case vi, it is observed that, under the loading area, compression index and coefficient of consolidation have been changed by altering positions of horizontal soil layers which are shown in Figures 9 and 12. Soil system has coarser soil particles in upper soil layers showing higher rate of consolidation and low compressibility. Considering Case i and Case ii of Figure 4, both the cases have three identical soil layers, but order of arrangement of these soil layers is different. Vertical loads are applied on the silty-clay soil surface for both Case i and Case ii of Figure 4, but, out of three layers, second layer of Case ii has more coarser soil than Case $i$ and because of that the amount of settlement is lower and the coefficient of consolidation is high for Case ii compared to Case i. Considering Case xiv and Case xv of Figure 4, load is directly applied on silty-sand soil surface for both the cases but the coefficient of consolidation is high for Case xv compared to Case xiv as the lower soil layer is coarser in Case Xv. The rate of consolidation does not only depend upon the soil on which the foundation is situated but also depend on all other possible soil layers which fall within the loaded area below the foundation.

8.3. Effects of Anisotropic Surrounding Vertical Soil Layers on 3D Consolidation Characteristics of Soil. Three-dimensional consolidation tests are performed on silty-clay soil and siltysand soil which are comprised of different vertical soil layers on two opposite sides as shown in Figure 5. Consolidative soil of Case i to Case vi shown in Figure 5 is silty-clay soil and of 
Case vii to Case xii shown in Figure 5 is silty-sand soil. Surrounding vertical soil layers which are placed on two opposite sides of consolidative soil are kept out of load distribution area as shown in Case ii of Figure 5. Compression index and coefficient of consolidation values are shown in Figures 10 and 13 for different cases of Figure 5, respectively. By analysing the test results, it is clear that different vertical soil layers which are placed on two opposite sides of consolidative soil have an immense effect on three-dimensional consolidation characteristics of soil. Surrounding soils have a confined force on the consolidative soil. If there are loose soils in surrounding areas then they create a less confined pressure compared to dense soil. In three-dimensional consolidation test, soil particles are allowed to move in vertical as well as in horizontal directions. If confined pressure increases then horizontal movements of soil particles are restrained and resultant vertical settlement decreases. From Figure 10, it is observed that, for the same consolidative soil, if adjacent vertical soil layers change then compression index values of that soil also get changed. By introducing denser adjacent vertical soil layers, compression index values of consolidative soil decrease and vice versa.

The adjacent vertical soil layers also have an immense effect on the rate of extraction of pore water. From Figure 13, it is observed that, with the introduction of coarser soil in the adjacent areas of consolidative soil, the coefficients of consolidation values increase due to increase of rate of extraction of pore water. Finer adjacent vertical soil layers resist the extraction of pore water and from Figure 13, it is observed that Case $\mathrm{x}$ has more coefficients of consolidation value compared to Case ix, in spite of having the same consolidative soil in both the cases of Figure 5. Similarly, from Figure 13, Case iv has more coefficients of consolidation value compared to Case iii in spite of having the same consolidative soil in both the cases of Figure 5.

\section{Practical Implications}

The conventional method of evaluation of settlement from the result of oedometer tests assumes that the soil only has vertical strain and there will be no lateral strain and it also assumes that the pore water dissipation only occurs in vertical direction and there will be no radial flow of water. The lateral confinement of soil sample in case of one-dimensional oedometer test is taken to be representative of the actual soil conditions. Presently developed three-dimensional consolidation apparatus allows the vertical as well as horizontal movement of soil particles and it also allows the vertical as well as radial flow of water during the consolidation process. In many practical cases $[20,21]$ it was seen that the time taken for actual field soil settlement is much smaller than the predicted time of settlement by traditional oedometer test.

In situ soils are subjected to different drainage conditions. The anisotropic permeability and drainage conditions influence the consolidation characteristics of in situ soils. In developed 3D consolidation apparatus, it is possible to control flow directions according to actual field flow conditions.

Nonhomogeneity of in situ soil is always overlooked at the time of laboratory or analytical evaluation of consolidation characteristics. In developed $3 \mathrm{D}$ consolidation apparatus, it is possible to control the nonhomogeneity according to actual field conditions.

\section{Conclusions}

By using a developed three-dimensional consolidation apparatus, the effects of anisotropic flow of pore water and anisotropy of soil on 3D consolidation characteristics of soil are evaluated. The effects of four different anisotropic flow conditions of pore water and fifteen different combinations of horizontal layered soils on three-dimensional consolidation of soil are assessed. Three-dimensional consolidation tests are also performed with different soils comprised of anisotropic vertical soil layers on two opposite sides. In these evaluations, the volume change method has been adopted to determine the compression index $\left(C_{c}\right)$ and the coefficient of consolidation $\left(c_{v}\right)$. The coefficient of consolidation has been determined by comparing the relationship between elapsed time, $t$ (in logarithmic scale), and dial gauge readings of the soil sample in the laboratory to the theoretical relationship (Taylor's method) between $T_{v}$ and $U$. The proposed solution permits solving the $3 \mathrm{D}$ consolidation problem, with different boundary conditions and based on the results and discussions made above, the following conclusions may be outlined:

(1) Experimental results show that the anisotropic permeability does not have any effect on initial and final surface settlements, but it has a great influence on surface settlement during the process of consolidation.

(2) The anisotropic flow of water has a great effect on the rate of consolidation of soil. With the increase of pore water flow restrictions, the rate of consolidation decreases.

(3) The rate of consolidation does not only depend upon the soil on which the foundation is situated but also depend on all other possible soil layers which fall within the stressed area below the foundation, but the upper soil layers are mostly affected by vertical surface load.

(4) Three-dimensional consolidation of soil allows horizontal strain of soil. Surrounding anisotropic vertical soil layers affect the horizontal movement of consolidating soil. Denser surrounding soil reduces the horizontal movements of consolidating soil compared to loose surrounding soils and this has an immense resultant effect on vertical consolidative settlement of soil.

\section{Notations}

A: Cross-sectional area of loading plate

$C_{c}$ : Compression index of soil for increasing effective stress

$c_{v}$ : Coefficient of consolidation

$D$ : Diameter of loading plate

e: Void ratio

$e_{0}$ : Initial void ratio

$G$ : Specific gravity of soil 


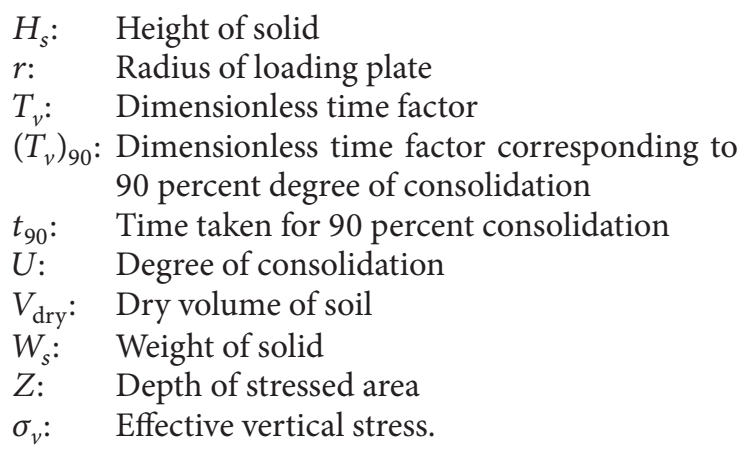

\section{Conflicts of Interest}

The authors declare that there are no conflicts of interest regarding the publication of this paper.

\section{Acknowledgments}

The authors are grateful to the Director of National Institute of Technology Agartala for providing necessary research facilities.

\section{References}

[1] C.-Y. Yune and Y.-H. Jung, "Application of multi-directional flow consolidometer for a constant rate of strain consolidation test under various drainage conditions," Geotechnical Testing Journal, vol. 35, no. 2, pp. 1-11, 2012.

[2] M. A. Biot, "General theory of three-dimensional consolidation," Journal of Applied Physics, vol. 12, no. 2, pp. 155-164, 1941.

[3] T. Edelman, "The consolidation of a layer which modulus of elasticity is proportional to depth," in Proceedings of the $3 \mathrm{rd}$ International Conference of Soil Mechanics, vol. 1, p. 358, Zurich, Switzerland, August 1953.

[4] A. W. Skempton and L. Bjerrum, "A Contribution to the settlement analysis of foundations on clay," Géotechnique, vol. 7, no. 4, pp. 168-178, 1957.

[5] D. Hwang and M. W. Witczak, "Multidimensional probabilistic consolidation," Journal of Geotechnical Engineering, vol. 110, no. 8, pp. 1059-1078, 1984.

[6] Z. Ai and Y. Cheng, "3-D consolidation analysis of layered soil with anisotropic permeability using analytical layer-element method," Acta Mechanica Solida Sinica, vol. 26, no. 1, pp. 62-70, 2013.

[7] Z. Y. Ai, Y. C. Cheng, W. Z. Zeng, and C. Wu, “3-D consolidation of multilayered porous medium with anisotropic permeability and compressible pore fluid," Meccanica. International Journal of Theoretical and Applied Mechanics, vol. 48, no. 2, pp. 491-499, 2013.

[8] A. R. Jumikis, Soilo Mechanics, Van Nostrand, Princeton, N.J, USA, 1962.

[9] G. De Josselin de Jong, "Application of stress functions to consolidation problems," in Proceedings of the 4th International Conference of Soil Mechanics and Foundation Engineering, pp. 320-323, London, UK, 1957.

[10] J. McNamee and R. E. Gibson, "Plane strain and axially symmetric problems of the consolidation of a semi-infinite clay stratum," The Quarterly Journal of Mechanics and Applied Mathematics, vol. 13, no. 2, pp. 210-227, 1960.
[11] N. Carrillo, "Simple two and three dimensional case in the theory of consolidation of soils," Journal of Mathematics and Physics, vol. 21, no. 1-4, pp. 1-5, 1942.

[12] D. W. Taylor, Fundamentals of Soil Mechanics, John Wiley \& Sons, New York, NY, USA, 1948.

[13] R. L. Schiffman and A. A. Fungaroli, "Consolidation due to tangential loads," in Proceedings of the 6th International Conference on Soil Mechanics and Foundation Engineering, pp. 188-192, Montreal, Canada, September 1965.

[14] J. R. Booker and J. C. Small, "A method of computing the consolidation behaviour of layered soils using direct numerical inversion of Laplace transforms," International Journal for Numerical and Analytical Methods in Geomechanics, vol. 11, no. 4, pp. 363-380, 1987.

[15] I. Vardoulakis and T. Harnpattanapanich, "Numerical LaplaceFourier transform inversion technique for layered-soil consolidation problems: I. Fundamental solutions and validation," International Journal for Numerical and Analytical Methods in Geomechanics, vol. 10, no. 4, pp. 347-365, 1986.

[16] E. Pan, "Green's functions in layered poroelastic half-spaces," International Journal for Numerical and Analytical Methods in Geomechanics, vol. 23, no. 13, pp. 1631-1653, 1999.

[17] J. Wang and S. Fang, "State space solution of non-axisymmetric Biot consolidation problem for multilayered porous media," International Journal of Engineering Science, vol. 41, no. 15, pp. 1799-1813, 2003.

[18] Z. Y. Ai and J. Han, "A solution to plane strain consolidation of multi-layered soils," in Proceedings of the GeoShanghai International Conference, pp. 276-283, Shanghai, China, June 2006.

[19] Z. Ai, Q. Wang, and C. Wu, "A new method for solving Biot's consolidation of a finite soil layer in the cylindrical coordinate system," Acta Mechanica Sinica, vol. 24, no. 6, pp. 691-697, 2008.

[20] J. M. Duncan, "Limitations of conventional analysis of consolidation settlement," Journal of Geotechnical Engineering, vol. 119, no. 9, pp. 1333-1359, 1993.

[21] S. Leroueil, "Tenth Canadian geotechnical colloquium: recent developments in consolidation of natural clays," Canadian Geotechnical Journal, vol. 25, no. 1, pp. 85-107, 1988. 

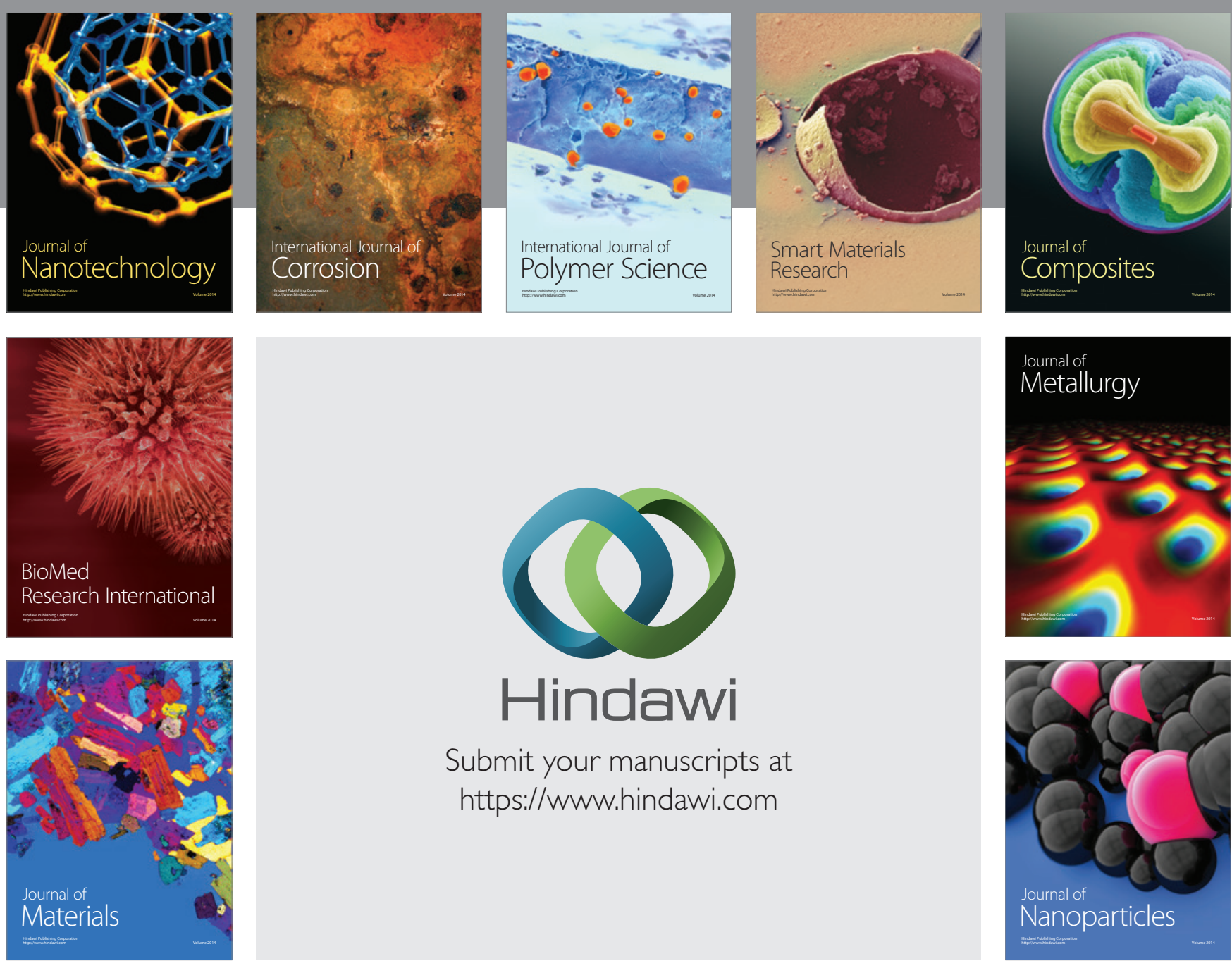

\section{Hindawi}

Submit your manuscripts at

https://www.hindawi.com

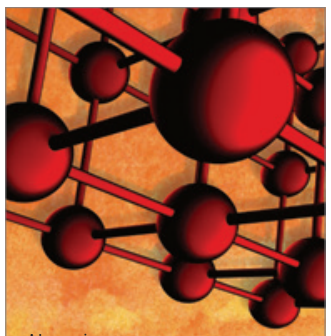

Materials Science and Engineering
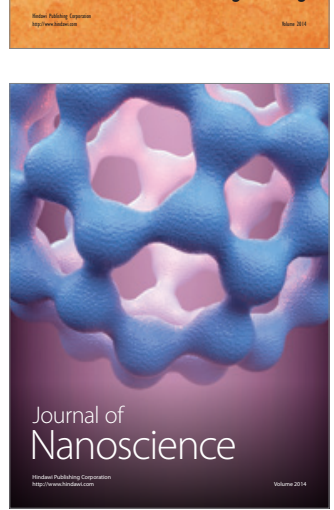
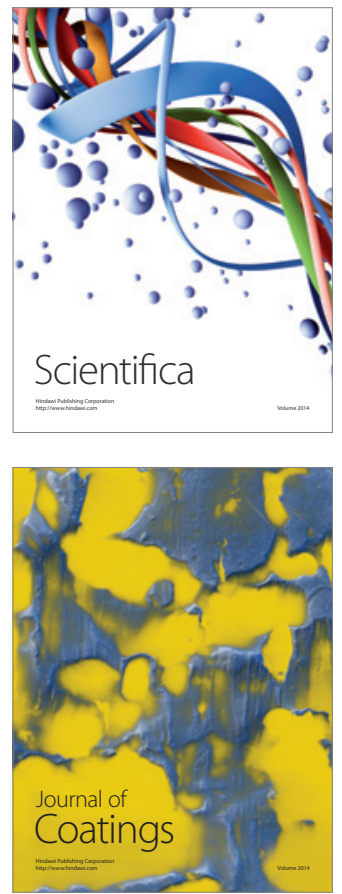
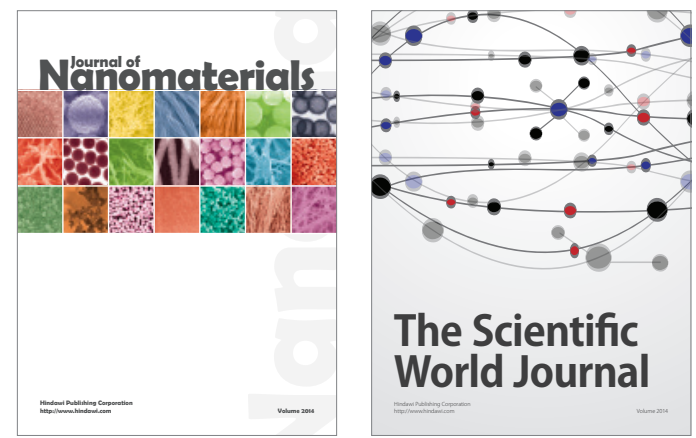

The Scientific World Journal
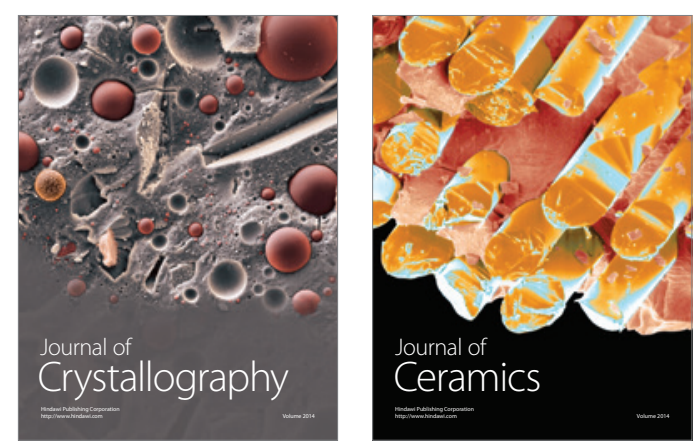
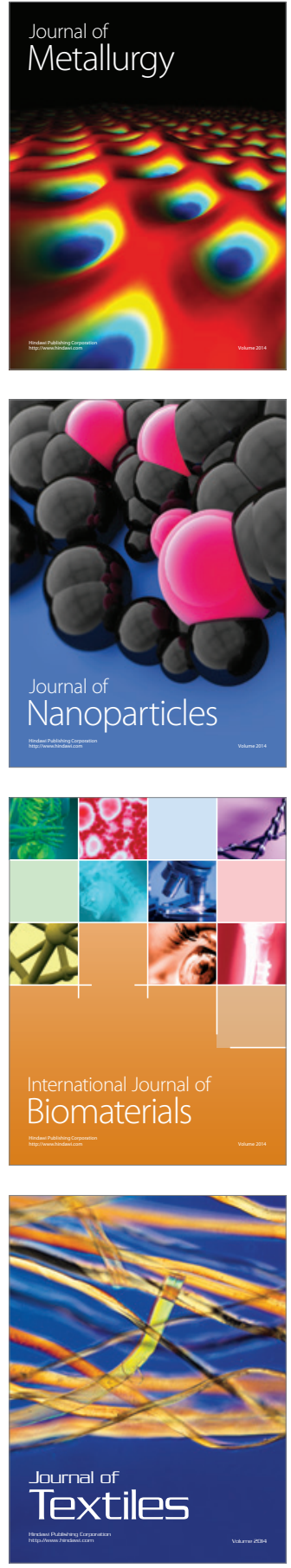